\title{
Distribution patterns of the barnacle, Chelonibia testudinaria, on juvenile green turtles (Chelonia mydas) in Bahia Magdalena, Mexico
}

\section{Patrones de distribución del balano, Chelonibia testudinaria, en tortugas verdes (Chelonia mydas) juveniles en bahía Magdalena, México}

\author{
Eduardo Nájera-Hillman ${ }^{1 凶}$, Julie B. Bass ${ }^{2,3}$ and Shannon Buckham ${ }^{2,4}$ \\ ${ }^{I}$ COSTASALVAjE A.C. Las Dunas \#160-203. Fracc. Playa Ensenada. 22880 Ensenada, Baja California, México. \\ ${ }^{2}$ Center for Coastal Studies-The School for Field Studies. 23740 Puerto San Carlos, Baja California Sur, México. \\ ${ }^{3}$ Wellesley College, 21 Wellesley College Rd., Wellesley, MA 02481 USA. \\ ${ }^{4}$ Whitman College, 345 Boyer Ave. Walla Walla, WA 99362 USA. \\ $\checkmark$ lalo_nate@yahoo.com.mx
}

\begin{abstract}
The barnacle, Chelonibia testudinaria, is an obligate commensal of sea turtles that may show population variability according to the physical characteristics of the environment and properties of turtle hosts; therefore, we characterized the distributional patterns and the potential effects on health of $C$. testudinaria on juvenile green turtles in Bahia Magdalena, Mexico. Barnacle attachment position, abundance, and size-class structure were described, while the relationship between barnacle abundance and turtle health condition and size was explored through generalized linear models. Juvenile green turtles of Bahía Magdalena offered an appropriate habitat for C. testudinaria as their frequency of occurrence was high and their abundance was similar to that found in other green turtle populations. Barnacles showed an aggregated distribution that may be facilitating their reproduction during the warm summer months. Barnacle abundance is unaffected by turtle size or seasonality, while their attachment position appears to be influenced by water flow over the turtle carapace and by plastron abrasion by the turtle against the sea floor. Healthier turtles exhibited a decreased barnacle load; therefore we suggest that $C$. testudinaria abundance may be a useful indicator of health for juvenile green turtles.
\end{abstract}

Key words: Baja California, carapace, Chelonia, epibionts, health, plastron.

Resumen. El balano Chelonibia testudinaria es un comensal obligado de tortugas marinas que puede presentar variaciones poblacionales de acuerdo a características ambientales y de las tortugas que coloniza; por lo tanto, caracterizamos su distribución y el efecto sobre la salud de tortugas verdes (Chelonia mydas) juveniles en bahía Magdalena, México. Se describieron la posición de adherencia, la abundancia y la estructura de tallas de C. testudinaria, mientras que la relación entre su abundancia y la salud y el tamaño de las tortugas se exploró a través de modelos lineales generalizados. Las tortugas verdes ofrecieron un hábitat adecuado para $C$. testudinaria ya que su presencia fue frecuente y su abundancia fue similar a la de otras poblaciones. C. testudinaria mostró una distribución agregada que puede facilitar su reproducción durante el verano. La abundancia de $C$. testudinaria no estuvo afectada por el tamaño de la tortuga o la temporada del año, mientras que se sugiere que la posición de adherencia estuvo afectada por el flujo del agua sobre el caparazón y la fricción del plastrón contra el fondo del mar. Las tortugas más saludables mostraron una disminución en la abundancia de balanos, por lo tanto sugerimos que C. testudinaria puede ser un indicador de la salud de las tortugas verdes juveniles.

Palabras clave: Baja California, caparazón, Chelonia, epibiontes, salud, plastrón.

\section{Introduction}

The barnacle Chelonibia testudinaria, is a prominent and conspicuous member of the sea turtle epibiont community associated with all 7 species of marine turtles worldwide (Zardus and Hadfield, 2004). Moreover, it is an obligate commensal that spends all of its adult life (lifespan

Recibido: 24 septiembre 2011; aceptado: 19 abril 2012 $\approx 3$ years; Hayashi and Tsuji, 2008) attached to these highly mobile hosts (Rawson et al., 2003). This epibionthost association, on which sea turtles have provided a mobile substrate for C. testudinaria (Bjorndal, 2003), has been found to exist in the fossil record as far back as 5-15 million years ago (Withers, 1953). Most sea turtle barnacle investigations have focused on the community structure associated with different sea turtle species (HernándezVázquez and Valadez-González, 1998; Schärer 2001; 
Pfaller et al., 2006; Pfaller et al., 2008; Fuller et al., 2010). However, few studies (Hayashi and Tsuji, 2008; Flint et al., 2010) have particularly investigated interactions between C. testudinaria and host green turtles (Chelonia mydas). For instance, although $C$. testudinaria is considered to be a commensal epibiont, it has been suggested that the number of $C$. testudinaria barnacles may be a health indicator in green sea turtles since it has been observed that the likelihood of a turtle being unhealthy increases with a higher plastron barnacle number (Flint et al., 2010). This negative impact on the turtle's health may be due to barnacles causing a significant amount of hydrodynamic drag, requiring the individual to expend more energy while swimming (Frick and Slay, 2000). Nevertheless, the value of barnacle epibiota estimations for assessing general health of sea turtle populations has not been fully explored and it remains controversial (Stamper et al., 2005; Flint et al., 2010), possibly because other factors such as turtle size may also influence the number of barnacles attached to sea turtles (Devin and Sadeghi, 2010).

Additionally, the distributional patterns of $C$. testudinaria on green sea turtles are partially understood and have been investigated only in a local context. This barnacle species is known to occur on an aggregated distribution on green turtles individuals (Hayashi and Tsuji, 2008); in other words, it is more likely that a turtle either has many barnacles or has none, rather than having a similar amount of barnacles on each turtle of the population or having a random distribution. Furthermore, it is known that $C$. testudinaria is more likely to occur on hard surfaces (e.g., carapace and plastron) over the turtle's body (Hernández-Vázquez and Valadez-González, 1998); especially on the carapace (Green, 1998; Alonso, 2007), on which it seems to prefer the posterior and marginal scutes (Matsuura and Nakamura, 1993; Pereira et al., 2006; Pfaller et al., 2006). However, this is not a generalized pattern (Fuller et al., 2010). Perhaps because the hard surfaces of a green turtle do not represent a surface of uniform quality to barnacles across green turtle populations or seasons. Moreover, recruitment and persistence of barnacles among regions of the turtle's hard surfaces could result from differential water flow patterns, food accessibility, and abrasion from contact with turtle flippers or hard objects (Pfaller et al., 2006). On the other hand, phylogeographic analyses have indicated that the populations of $C$. testudinaria are highly divergent from one another, even within the same ocean basins (Rawson et al., 2003). Thus, C. testudinaria barnacles may show inherent population particularities as well as population features influenced by the physical characteristics of the environment and/or properties of turtle hosts (e.g., density, size, carapace region preference).
The numerous estuaries of Bahia Magdalena, Mexico, represent a distinctive habitat type for $C$. testudinaria. These estuaries comprise a unique combination of environmental conditions (see study area) and they are important developmental areas for juvenile green turtles (straight carapace length $<77 \mathrm{~cm}$ ), some of which utilize estuaries as foraging grounds for up to 20 years (Koch et al., 2007). Green turtles in Bahia Magdalena are recognized as a distinctive genetic subpopulation that is confined to the eastern Pacific Ocean and largely isolated from other Pacific green turtle populations in Asia, the Indo-Pacific region, and Hawaii (Pritchard, 1999). To date there are no studies that characterize the distributional patterns and the potential effects that $C$. testudinaria colonization has on the health of green turtles from this unique subpopulation. This study presents information on C. testudinaria attachment position, abundance, and size-class structure from green turtles captured at Bahia Magdalena. Using linear models we examine relationships between the aforementioned data and turtle size and turtle health. Our results are compared to data on green turtles from other areas, and we discuss our findings with respect to information collected from other sea turtle species.

\section{Materials and methods}

Study area. The estuaries of Bahia Magdalena (Fig. 1) generally consist of shallow $(<9 \mathrm{~m})$ channels with substrates composed of sand and mud interspersed with patches of algae and sea grass beds. They are surrounded by mangroves (Koch et al., 2007), which, in combination with seasonal upwellings at the primary entrance of the bay, make this a highly productive ecosystem (MaedaMartínez et al., 1993). Tidal currents within the estuaries are strong (mixed semidiurnal, amplitude: 1-2.3 m), and water temperatures vary between summer (May to October; $25.9^{\circ} \mathrm{C} \pm 2.1 \mathrm{SD}$ ) and winter (November to April; $\left.20.3^{\circ} \mathrm{C} \pm 1.9 \mathrm{SD}\right)$. Yearly precipitation is low $(<100 \mathrm{~mm} /$ year) and salinity levels are consistently high around 36-40 PSU (Alvarez-Borrego et al., 1975; Koch et al., 2005).

Data collection and analysis. As part of a long term sea turtle monitoring program in Bahia Magdalena, we captured, measured, and tagged green turtles between February 2010 and April 2011, following the procedures of Koch et al. (2007) from the Banderitas, San Buto, and Santo Domingo estuaries within Bahia Magdalena, Baja California Sur (Fig. 1). Turtle straight carapace length (SCL, from notch to tip of distal marginal scute) and straight carapace width (SCW) were measured with metal forester's callipers to the nearest $0.1 \mathrm{~cm}$. Turtles were weighed to the nearest kilogram using a spring scale and a piece of seine netting. The maximum basal diameter 


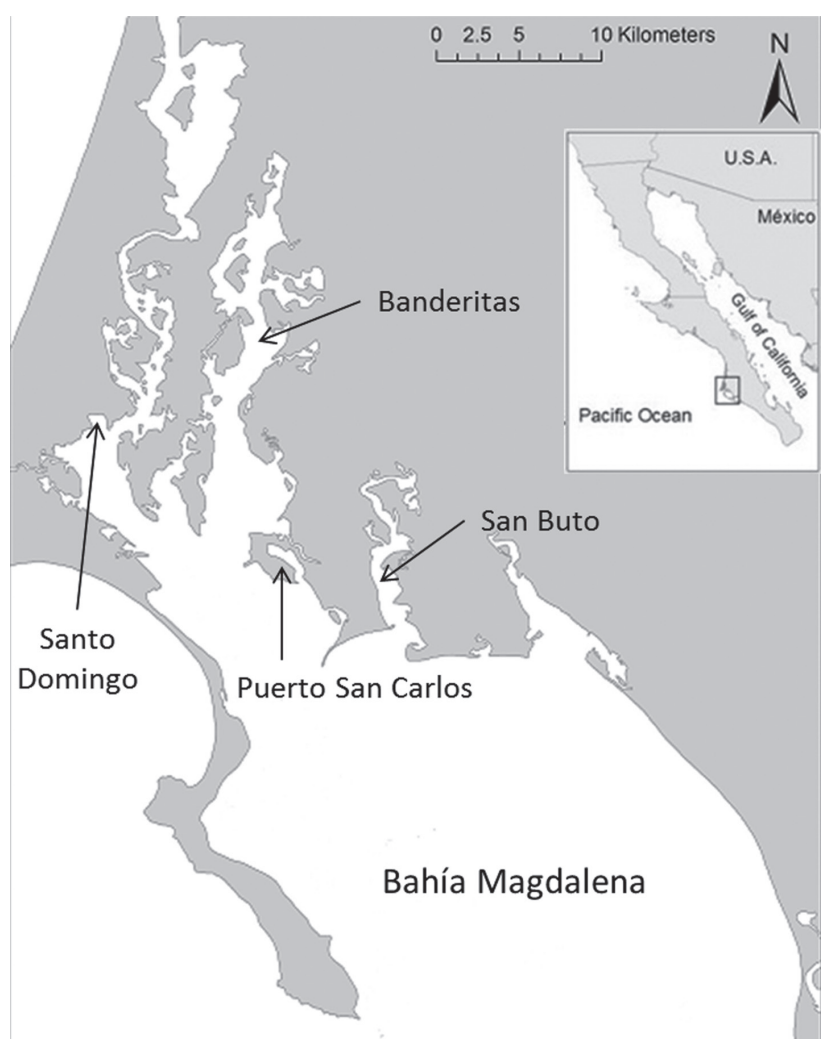

Figure 1. Study area. Locations of estuaries sampled during this investigation are indicated with arrows as well as the town of Puerto San Carlos. Inset: depicts location of Bahia Magdalena in the Baja California Peninsula, Mexico.

(MBD) of barnacles attached to turtles was also recorded and barnacle location was indicated from each turtle using a matrix that separates both the turtle's dorsal and ventral regions into 6 sub-regions following an anterior to posterior order (Fig. 2).

Because the sea turtle body represents a restricted, mobile patch of substrate for barnacles to attach, we used an aggregation model: the $J$ index (Sevenster, 1996), after Hayashi and Tsuji (2008), to measure the degree of C. testudinaria aggregation. This model quantifies the increase in the average density of barnacles encountered relative to a random distribution, using the following formula:

$$
I=\left(\sum \frac{e_{i}}{N^{2}}\right)\left\{\sum \frac{\llbracket n_{i}\left(\square \rrbracket n_{i}-1\right)}{e_{i}}\right\}-\mathbf{1}
$$

where $n_{i}$ is the number of barnacles found on turtle $i, e_{i}$ is the size of turtle $i$, quantified by the square measure of the turtle carapace [straight carapace length $(\mathrm{SCL}) \times$ straight carapace width (SCW) in $\left.\mathrm{cm}^{2}\right]$, and $N$ is the total number of barnacles. $J=0$ indicates a random distribution, $J>0$ an aggregated distribution, and $J<0$ the tendency to a uniform distribution.

Additionally, we calculated the turtle's body condition index (BCI) with SCL and weight (W) measurements from each turtle, using the following formula (Bjorndal et al., 2000):

$$
B C I=\left(\frac{W}{S C L^{3}}\right) \times 10,000
$$

The BCI was then used to evaluate the effect of presence/absence of $C$. testudinaria on green turtle health by comparing ( $t$-test) turtles with and without barnacles. Currently, the BCI is the most cited and most widely used health index in sea turtle health-assessment studies (Labrada-Martagón et al., 2010), as it is intimately related to an animal's health and has been widely claimed to be an important determinant of fitness (Peig and Green, 2010). Additionally, we used a Generalized Linear Model (GLM) to determine if turtle size and turtle BCI had a significant influence on $C$. testudinaria abundance. A major advantage of the GLM is that it can integrate data from different statistical distributions (e.g., normal in multiple regression, binomial for presence/absence data, Poisson or negative binomial for species individual counts; McCullagh and Nelder, 1989) with the appropriate modelling of statistical error. The counts of $C$. testudinaria, recorded for each captured turtle, approximated a Poisson distribution. Therefore, we conducted a Quasi-Poisson multiple regression with a log link function and dispersion parameter of 5.09 to assess the association between turtle size and BCI with barnacle abundance. Correlated explanatory variables may affect the reliability of the regression parameters (e.g., estimate and $p$ values) and make it difficult to accurately interpret the results (Berry and Feldman, 1985; Hutcheson and Sofroniou, 1999). Therefore, we checked if our variables were correlated in order to assess if the multivariate model was reliable. All statistical analyses were performed using R 2.13.1 (http:// www.r-project.org/).

As the sampling was conducted year-round, the present investigation offered the opportunity to make seasonal comparisons. Thus, data for barnacle sizeclass structure and abundance were pooled together into summer (May-October) and winter (November-April) seasons. The barnacle abundance and size data were not normally distributed (Shapiro-Wilk's test, $p<0.05$ ), and nonparametric statistical tests were therefore applied. The number of barnacles per turtle was compared between seasons with a Mann-Whitney $U$ test for samples with 

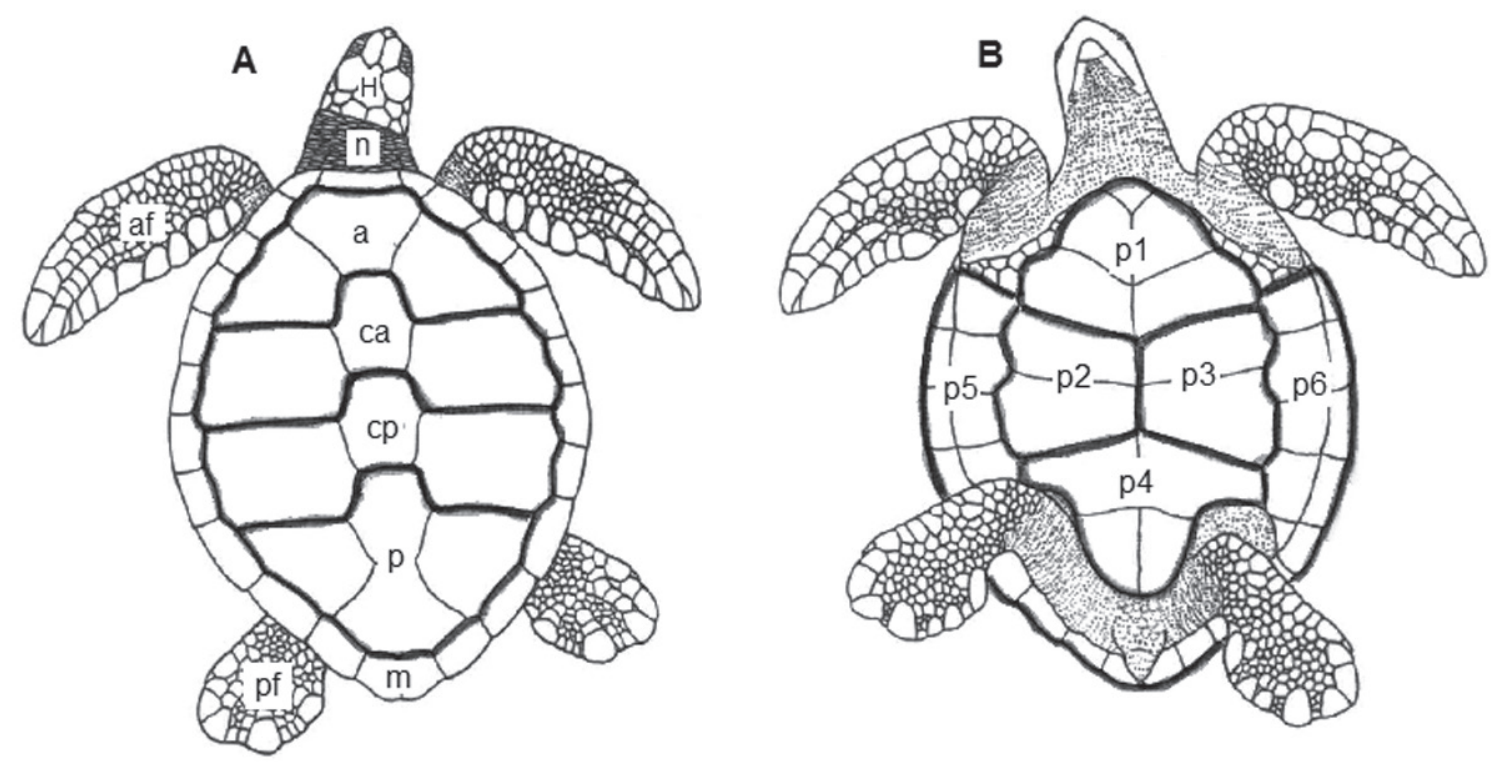

Figure 2. Diagrammatic representation of A), the dorsal view and B), the ventral view of a green turtle (Chelonia mydas). Dorse regions are identified as: A), for anterior scutes; CA), for central anterior scutes; CP), for central posterior scutes; M), for marginal scutes; the soft body parts region grouped the head $(\mathrm{H})$, the neck $(\mathrm{N})$, and the anterior $(\mathrm{AF})$ and posterior flippers $(\mathrm{PF})$. The plastron was divided into regions P1 to P6. Modified illustrations of Tom McFarland in Pritchard and Mortimer (1999).

non-normal distributions, and the barnacle maximum basal diameter was compared through a $t$-test for samples with unequal variances.

\section{Results}

A total of 72 green turtles were captured and released. All turtles were juveniles (44.6-65 cm SCL), with the exception of one adult individual $(86.2 \mathrm{~cm} \mathrm{SCL})$. A total of $49(68 \%)$ turtles hosted C. testudinaria, and a total of 169 C. testudinaria were measured. Additionally, 7 individuals of the barnacle species Platylepas hexastylos were found from 2 turtles that also hosted $C$. testudinaria. Due to the low number of $P$. hexastylos we did not include them in our analyses. Overall barnacle abundance ranged from 1 to 19 individuals per turtle (mean $=4.1 \pm 3.9 \mathrm{SD})$, and MBD ranged from 0.2 to $7.2 \mathrm{~cm}$ (mean=2.88 cm $\pm 1.57 \mathrm{SD})$. Barnacles were more abundant on the carapace region $(74 \% ; n=125)$ than on the plastron region $(18.3 \% ; n=31)$, and only few barnacles were observed on soft regions of the turtle's body (head, neck, and flippers; 7.7\%; $n=13$ ). In particular, the greater abundance of barnacles was observed on the central scutes (regions $\mathrm{CA}$ and $\mathrm{CP}$ ) of the carapace region (Fig. $3 \mathrm{~A}$ ). Barnacles on the plastron region were more commonly observed along the margins (regions P5 and P6) and on the anterior region (region P1) (Fig. 3B). The distributional pattern of $C$. testudinaria represented by the $J$ index showed an aggregated distribution $(J=5.08)$ indicating that turtles either hosted many barnacles or none at all.
The BCI of green turtles varied between 1.03 and 1.74 with an overall mean and standard deviation of $1.44 \pm$ 0.15 . Turtles with barnacles had a lower BCI (mean $=1.43$ $\pm 0.04 \mathrm{SD}$ ) than turtles without barnacles (mean $=1.46$ $\pm 0.02 \mathrm{SD}$ ); however, this difference was not significant ( $t$-test: $p=0.44, \alpha=0.05 ;$ Fig. 4). Alternatively, since turtle size and BCI were not correlated $(r>0.01, p=0.94)$, the results from the multivariate analysis were considered to be reliable and showed a significant negative association between turtle BCI and barnacle abundance (Table $1 ; p=0.016$ ), but no significant association between

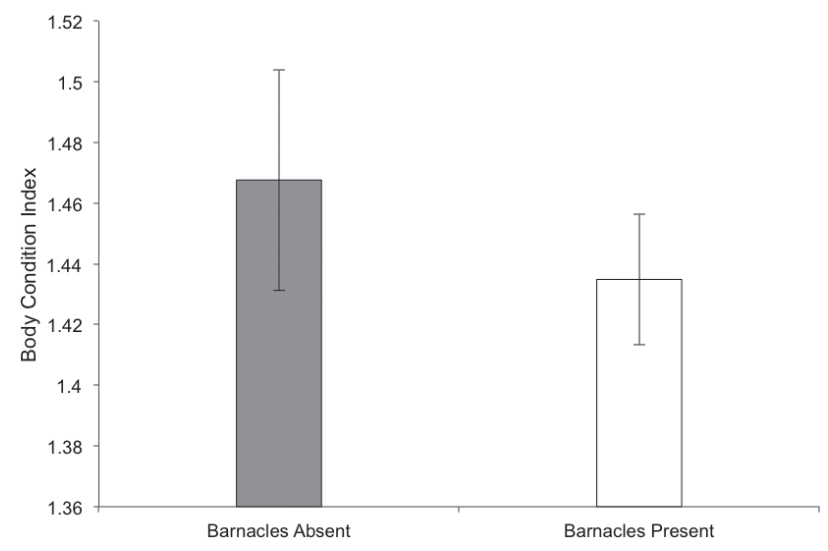

Figure 4. Mean body condition index of green turtles (Chelonia mydas $)$ with $(\mathrm{n}=49)$ and without $(\mathrm{n}=23) C$. testudinaria barnacles in Bahia Magdalena, Baja California Sur Mexico. Error bars denote standard deviation. 


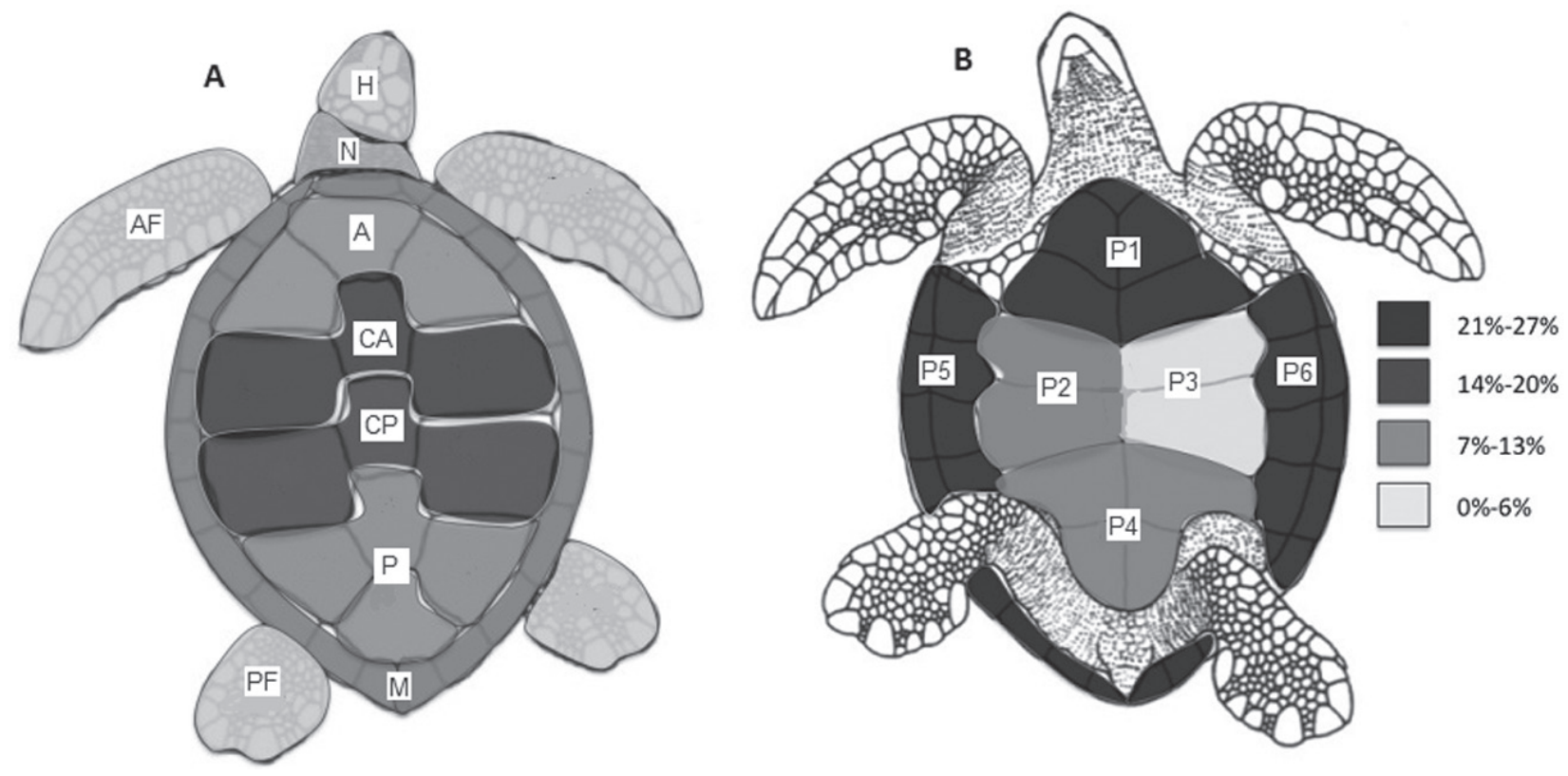

Figure 3. Relative abundance of Chelonibia testudinaria in A), 6 regions of the dorse and B), 6 regions of the plastron of juvenile Chelonia mydas from estuaries of Bahia Magdalena, Baja California Sur, Mexico.

Table 1. Summary results of the multivariate GLM analysis (Quasi-Poisson family, log link function), considering the influence of the interaction between green turtle (Chelonia mydas) size and body condition index (BCI) on Chelonibia testudinaria abundance in Bahia Magdalena, Mexico

\begin{tabular}{lcccc}
\hline & Estimate & $S E$ & $T$ & $P$ \\
\hline Intercept & 8.63 & 5.19 & 1.663 & 0.101 \\
Turtle size & -0.0021 & 0.0022 & -0.961 & 0.340 \\
Turtle BCI & -4.74 & 3.346 & -1.417 & 0.0161 \\
Turtle size-BCI & 0.0012 & 0.0013 & 0.888 & 0.378 \\
\hline
\end{tabular}

turtle size and barnacle abundance (Table $1 ; p=0.34$ ). Moreover, the multivariate model also indicated a nonsignificant interaction between turtle size and turtle BCI in determining the number of barnacles on green turtles in Bahia Magdalena (Table $1 ; p=0.38$ ).

The mean number of barnacles per turtle was similar between seasons (Mann-Whitney $\mathrm{U}: p=0.94, \alpha=0.05$; winter= $4.4 \pm 4.8 \mathrm{SD}$; summer=3.8 $\pm 3.1 \mathrm{SD}$ ). However, the seasonal comparison of barnacle size-class distribution revealed that during summer smaller size-classes $(\leq 3$ $\mathrm{cm})$ were more abundant, while during winter larger size-classes $(>3 \mathrm{~cm})$ dominated the population; in fact, barnacles larger than 6 centimetres were only observed during winter (Fig. 5). Likewise, the barnacle MBD was significantly different $(t$-test: $p<0.0001, \alpha=0.05)$ between seasons, with smaller barnacles in summer (mean $=2.47 \mathrm{~cm}$ $\pm 1.53 \mathrm{SD} ; \mathrm{n}=82)$ and larger barnacles in winter (mean= $3.39 \mathrm{~cm} \pm 1.48 \mathrm{SD} ; \mathrm{n}=87)$.

\section{Discussion}

The frequency of occurrence of C. testudinaria on juvenile green sea turtles in Bahia Magdalena was high $(68 \%)$, similar to that found in other foraging populations of juvenile green turtles (e.g., 62\%; de Loreto and Vigliar Bondioli, 2008). Nevertheless, the frequency of occurrence of this barnacle species may vary widely between or even within green turtle populations (Green, 1998; Bugoni et al., 2001; Pereira et al., 2006; Alonso, 2007; Fuller et al., 2010). For example, the frequency of occurrence of $C$. testudinaria on juvenile green sea turtles from feeding grounds in the southwestern Atlantic ranges from 11 to 100\% (Bugoni et al., 2001; Pereira et al., 2006; Alonso, 2007). Because many factors influence sea turtle behavior, such as predation, physical stress, disturbance, and competition, and because turtle behavior certainly influences the occurrence of $C$. testudinaria on sea turtles 


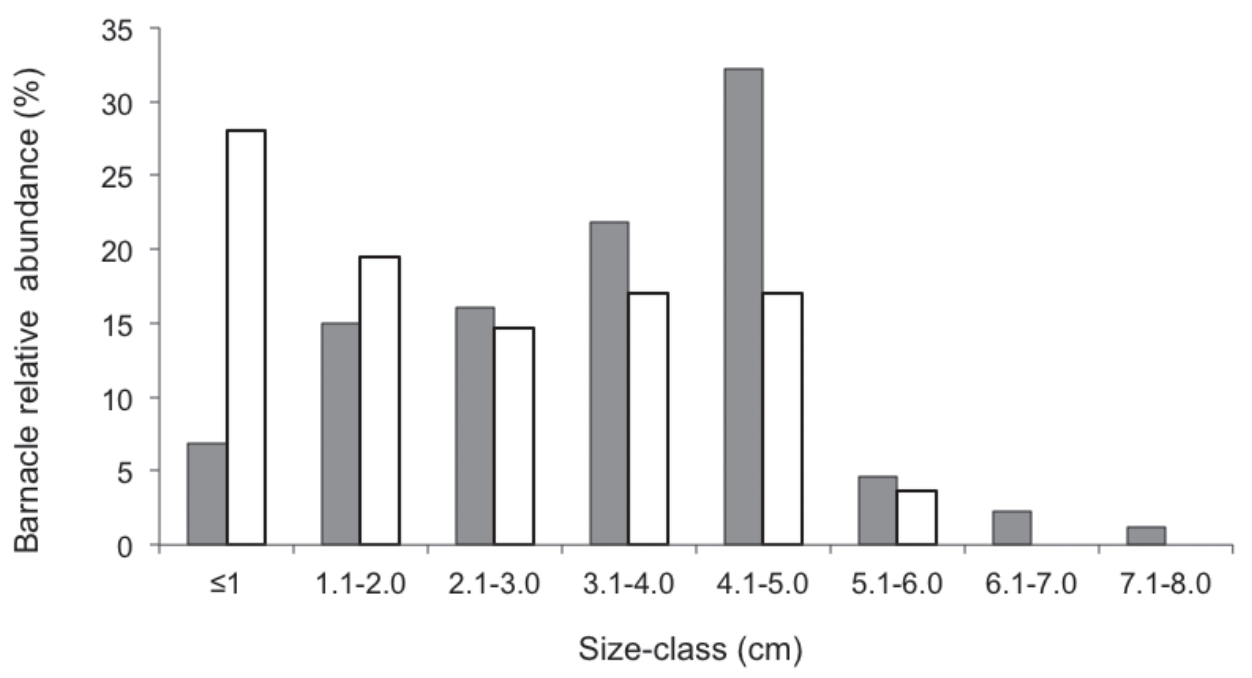

Figure 5. Size-class distribution of Chelonibia testudinaria found in Chelonia mydas during summer (white columns; $\mathrm{n}=82$ ) and winter (grey columns; $\mathrm{n}=87$ ) in estuaries of Bahia Magdalena, Baja California Sur, Mexico.

(Frick et al., 2000), it is difficult to draw conclusions about which factors may be influencing the frequency of occurrence of $C$. testudinaria in Bahia Magdalena. Nonetheless, Bahia Magdalena estuaries represent a habitat where juvenile green turtles aggregate to feed and, therefore, occur at appreciable densities and for sufficient lengths of time (Koch et al., 2007) to allow barnacle larvae time to emerge, develop in the plankton, and recruit in adequate abundance for reproduction. Such explains, at least in part, the high frequency of occurrence of $C$. testudinaria observed in this investigation. Moreover, it is known that $C$. testudinaria needs receptive neighbors for cross-fertilization during breeding (Zardus and Hadfield, 2004); thus, it is not surprising that barnacles were found to aggregate on green turtles in Bahia Magdalena $(J=$ $5.08)$ as it has been observed in green turtles populations on the coasts of Japan ( $J=6.87$; Hayashi and Tsuji, 2008). Additionally, barnacle abundance on juvenile green turtles (1 to 19 barnacles/turtle) in Bahia Magdalena was similar to that found from other green turtles in near shore habitats (1 to 33 barnacles/turtle), such as feeding grounds (Bugoni et al., 2001; Pereira et al., 2006; Alonso, 2007) or nesting beaches (Fuller et al., 2010). What is more, although the breeding cycle and reproduction frequency of $C$. testudiaria remains unknown (Zardus and Hadfield, 2004), and barnacle abundance did not vary between seasons, the differential seasonal size-class distribution observed in our results (Fig. 5) may be an indication that $C$. testudinaria in Bahia Magdalena reproduces more actively during summer, when the highest frequency of smaller post-settlement individuals occurs. It is also feasible that the different barnacle seasonal size-class distribution is a result of the molting of the outer carapace layer that occurs approximately every year in green sea turtles (Monroe, 1981). However, it is unknown if molting occurs simultaneously in all turtles of the population.

The general attachment position of C. testudinaria on green turtles of Bahia Magdalena was consistent with the notion that barnacles are more abundant in the carapace followed by the plastron, and just few individuals are found in the soft regions of the body (Green, 1998; HernándezVázquez and Valadez-González, 1998; Alonso, 2007). However, barnacles were more abundant in the central scutes of the turtle's carapace (Fig. 3A), in contrast with studies that report $C$. testudinaria predominantly from the posterior portion of the carapace of green turtles examined elsewhere (Pereira et al., 2006; Fuller et al., 2010) and of loggerhead turtles from the northwestern Atlantic (Frick et al., 1998). The dynamics of recruitment and survival of epibionts on sea turtle carapaces are affected by a complex set of interactions, including water flow patterns over the carapace, turtle behavior patterns, interactions among epibionts, and tolerance to desiccation and physical trauma (Pfaller et al., 2006). Water flow patterns appear to be the greatest influence on the settlement and growth of filter feeders like barnacles on sea turtles (Bjorndal, 2003). The posterior scutes of the turtle's carapace have lower flow rates whereas the anterior scutes have a higher rate (Schärer, 2001; Larsson and Jonsson, 2006). As seen in our results, barnacles were more abundant in the central scutes of the carapace, where water flow may be moderate, allowing for maximum foraging potential. Likewise, it has also been suggested that $C$. testudinaria occur in greater densities in the vertebral zones compared to marginal 
zones of the carapace (Matsuura and Nakamura, 1993; Pfaller et al., 2006). Moreover, resting turtles often place their front flippers over the marginal scutes, which may impede colonization and contribute to the lower density of barnacles there (Pfaller et al., 2006), as seen in our results. We cannot neglect that interactions among barnacle species (e.g., competition) may play a role on the distribution patterns of $C$. testudinaria. However, since we only found 7 individuals of $P$. hexastilos on 2 turtles, which also had $C$. testudinaria, we cannot assess the effects of this interaction. The distributional pattern of $C$. testudinaria on the plastron surface has not been previously investigated. Nevertheless, physical trauma when the green turtles scrapes against the sea floor while they forage for algae and seagrasses (LópezMendilaharsu et al., 2005) will remove some barnacles; especially those on the central regions of the plastron. The marginal regions of the plastron are in less contact with the sea bottom simply because of their uplifted position. Additionally, it can be assumed that turtles have to lift the base of their necks in order to forage from the bottom, thus the anterior region of the plastron would suffer less friction contributing to the higher abundance of barnacles there (Fig. 3B). Whether the differential distribution of epibionts over the carapace, the plastron surfaces, or both is a result of differential recruitment to regions of the carapace and plastron, differential survival in these regions, or a combination of the 2, is still to be determined (Pfaller et al., 2006).

Our results indicate that in Bahia Magdalena barnacle abundance is not correlated with turtle size (Table 1) as previously observed in other $C$. testudinaria/green turtle populations (Hayashi and Tsuji, 2008). However, it is known that small green turtles spend the first portion of their lives (from hatchling to subadult; $5-30 \mathrm{~cm}$ ) in oligotrophic oceanic waters (Reich et al., 2007), which may be an unsuitable habitat for this filter-feeding barnacle species (Rawson et al., 2003; Zardus and Hadfield, 2004). Consequently, small turtles are devoid of barnacles and may be considered as outliers for analyses of the influence of turtle size on barnacle abundance. Nevertheless, we did not have these kind of outliers in our sample simply because we did not capture small individuals $(<44.6 \mathrm{~cm})$, which may be arriving to Bahia Magdalena from habitats in which barnacles does not access or adhere easily to them (Nichols, 2003). On the other hand, the effects of C. testudinaria on the green turtle's health are poorly understood. It has been suggested that barnacles may have potential negative effects, such as increased drag (Logan and Morreale, 1994), or benefits, such as cryptic protection from predators (Frazier et al., 1991). Although no observable effects on turtle BCI can be identified by the comparison of turtles with and without $C$. testudinaria barnacles (Fig. 4), our results indicate that $C$. testudinaria loads (abundance) in Bahia Magdalena are related to green turtle BCI as observed in the Quasi-Poisson regression between the turtle's $\mathrm{BCI}$ and the number of barnacles per turtle (Table $1 ; p=0.016$ ). Differences in physical, and/ or behavioral properties of healthy turtles vs. unhealthy turtles may account for the variations in the abundance of barnacles. For example, turtles might have a substance that repels barnacles, which might differ in the quality and in the amount produced between individuals (Hayashi and Tsuji, 2008). On the other hand, it can be argued that unaccounted interactions between other variables such as turtle size or season may be producing misleading results about the effects of barnacles on sea turtle health. However, we did not find a significant difference between the abundance of barnacles between summer and winter (Mann-Whitney $\mathrm{U}: p=0.94, \alpha=0.05$ ) and the multivariate model for assessing the interaction of turtle size and BCI in determining the number of barnacles proved to be not significant (Table $1 ; p=0.38$ ). Other specialized indicators of general health status such as hematologic parameters or plasma enzyme chemistries may be a practical marker for sea turtle population health (Stamper et al., 2005). Nevertheless, their application remains controversial. For example, based on biochemical and haematological parameters, it has been suggested that an increased load of C. testudinaria is indicative of poor health in green sea turtles (Flint et al., 2010). However, no effects have been found using the same health parameters in loggerhead turtles colonized by C. testudinaria (Stamper et al., 2005). Given the controversial use of haematological parameters to assess the impact of $C$. testudinaria over sea turtle health, and since BCI is a well-accepted parameter of sea turtle health (Bjorndal et al., 2000; Koch et al., 2007; Labrada-Martagón et al., 2010), we consider barnacle load to be an alternative indicator of green turtle health which is easily quantifiable in the field.

In summary, juvenile green turtles in Bahia Magdalena offer an appropriate habitat for C. testudinaria since barnacle frequency of occurrence was high and the number of barnacles per turtle was similar to that found in other green turtle populations. Moreover, barnacles showed and aggregated distribution that may be facilitating their reproduction during the warm summer months. Barnacle abundance seems not to be affected by turtle size or season, while their attachment position seems to be affected mainly by carapace water flow and plastron abrasion against the sea floor. Additionally, turtles within this study exhibited a decreased barnacle load (abundance) in relation with turtle BCI (healthier turtles have less barnacles); therefore we suggest that $C$. testudinaria may be a useful indicator of health condition for green sea turtles in Bahia Magdalena. 


\section{Acknowledgements}

We would like to thank all School for Field Studies Mexico students and staff who participated in the fieldwork activities; especially our field technicians Alfonso Romero, Felipe Inzunza, and Cipriano Romero, and to the centre director Gustavo Hinojosa. Also we would like to thank to the Dirección de Vida Silvestre of SEMARNAT for the permits granted to conduct this investigation. This work would not have been possible without the support of SFS interns April Hensley and Nicole Brandt.

\section{Literatura cited}

Alonso, L. 2007. Epibiontes asociados a la tortuga verde juvenil (Chelonia mydas) en el área de alimentación y desarrollo de Cerro Verde, Uruguay. Bachelors Thesis, Universidad de Buenos Aires, Argentina. 60 p.

Alvarez-Borrego, S., L. A. Galindo-Bect and A. Chee-Barragan. 1975. "Caracteríticas hidroquímicas de Bahía Magdalena, B.C.S." Ciencias Marinas 2:94-110.

Berry, W. D. and S. Feldman. 1985. Multiple regression in practice. Sage Publications. Newburry. 96 p.

Bjorndal, K. A. 2003. Roles of loggerhead sea turtles in marine ecosystems. In Loggerhead sea turtles, A. B. Bolten and B. E. Witherington (eds.). Washington, D.C. Smithsonian Books. p. $235-254$

Bjorndal, K. A., A. B. Bolten and M. Y. Chaloupka. 2000. Green turtle somatic growth model: Evidence for density dependence. Ecological Applications 10:269-282.

Bugoni, L., L. Krause, A. O. de Almeida and A. A. de Pádua Bueno. 2001. Commensal barnacles of sea turtles in Brazil. Marine Turtle Newsletter 94:7-9.

de Loreto, B. O. and A. C. Vigliar-Bondioli. 2008. Epibionts associated with green sea turtles (Chelonia mydas) from Cananéia, southeast Brazil. Marine Turtle Newsletter 122:58.

Devin, M. L. and P. Sadeghi. 2010. Barnacles on hawksbill sea turtles, Eretmochelys imbricate, in Hormoz Island, Iran (Reptilia: Cheloniidae). Zoology in the Middle East 49:4548.

Flint, M., J. M. Morton, C. J. Limpus, J. C. Murray, P. J. PattersonKane and P. C. Mills. 2010. Development and application of biochemical and haematological reference intervals to identify unhealthy green sea turtles (Chelonia mydas). The Veterinary Journal 185:299-304.

Frazier, J., I. Goodbody and C. A. Ruckdeschel. 1991. Epizoan communities on marine turtles. II. Tunicates. Bulletin of Marine Sciences 48:763-765.

Frick, M. G. and C. K. Slay. 2000. Caretta caretta (loggerhead sea turtle) epizoans. Herpetological Review 31:102-103.

Frick, M. G., K. L. Williams and M. Robinson. 1998. Epibionts associated with nesting loggerhead sea turtles (Caretta caretta) in Georgia, USA. Herpetological Review 29:211214.

Frick, M. G., K. L. Williams, D. Veljacic, L. Pierrard, J. A. Jackson and S. E. Knight. 2000. Newly documented epibiont species from nesting loggerhead sea turtles (Caretta caretta) in Georgia, USA. Marine Turtle Newletter 88:3-5.

Fuller, W. J., A. C. Broderick, R. Enever, P. Thorne and B. J. Godley. 2010. Motile homes: a comparison of the spatial distribution of epibiont communities on Mediterranean sea turtles. Journal of Natural History 44:1743-1753.

Green, D. 1998. Epizoites of Galapagos green turtles. Proceedings of the Sixteenth Annual Symposium on Sea Turtle Biology and Conservation NOAA-Technical Memorandum NMFSSEFSC-412:63.

Hayashi, R. and K. Tsuji. 2008. Spatial distribution of turtle barnacles on the green sea turtle, Chelonia mydas. Ecological Research 23:121-125.

Hernández-Vázquez, S. and C. Valadez-González. 1998. Observaciones de los epizoarios encontrados sobre la tortuga golfina Lepidochelys olivacea en La Gloria, Jalisco, México. Ciencias Marinas 24:119-125.

Hutcheson, G. and N. Sofroniou. 1999. The multivariate social scientist. Sage Publications. Trowbridge, Wiltshire. 288 p.

Koch, V., L. B. Brooks and W. J. Nichols. 2007. Population ecology of the green/black turtle (Chelonia mydas) in Bahía Magdalena, México. Marine Biology 153:35-46.

Koch, V., S. J. M. Mazón, F. Sinsel, R. M. Mungaray and D. Dunn. 2005. Lion's paw scallop (Nodipecten subnodosus, Sowerby 1835) aquaculture in Bahía Magdalena, México: effects of population density and season on juvenile growth and mortality. Aquaculture Research 26:505-512.

Labrada-Martagón, V., L. C. Méndez-Rodríguez, S. C. Gardner, V. H. Cruz-Escalona and T. Zenteno-Savín. 2010. Health indices of the green turtle (Chelonia mydas) along the Pacific coast of Baja California Sur, Mexico. II. Body condition index. Chelonian Conservation and Biology 9:173-183.

Larsson, A. I. and P. R. Jonsson. 2006. Barnacle larvae actively select flow environments supporting post-settlement growth and survival. Ecology 87:1960-1966.

Logan, P and S. J. Morreale. 1994. Hydrodynamic drag characteristics of juvenile L. kempi, C. mydas, and C. caretta. In Proceedings of the Thirteenth Annual Symposium on Sea Turtle Biology and Conservation, B. A. Schroeder and B. E. Witherington (eds.). NOAA-Technical Memorandum NMFS-SEFSC-341:248-252.

López-Mendilaharsu, M., S. Gardner, J. A. Seminoff and R. Riosmena-Rodriguez. 2005. Identifying critical foraging habitats of the green turtle (Chelonia mydas) along the Pacific coasts of the Baja California peninsula, Mexico. Aquatic conservation: marine and freshwater ecosystems 15:259-269. 
Maeda-Martínez, E. N., T. Reynoso, F. Solis, A. Leija, D. Aureoles, C. Salinas, D. Lluch-Cota and P. Ormat. 1993. A model to explain the formation of catarina scallop Argopecten circularis (Sowerby 1835) beds in Magdalena Bay, Mexico. Aquatic Fisheries Management 24:323-339.

Matsuura, I. and K. Nakamura. 1993. Attachment pattern of the turtle barnacle Chelonibia testudinaria on carapace of nesting loggerhead turtle, Caretta caretta. Nippon Suisan Gakkai Shi 59:1803.

McCullagh, P. and J. A. Nelder. 1989. Generalized linear models. $2^{\text {nd }}$ ed. London, Chapman and Hall. 300 p.

Monroe, R. 1981. Studies in the Coronulidae (Cirripedia): shell morphology, growth, and function, and their bearing on subfamily classification. Memoirs of the Queensland Museum 20:237-251.

Nichols, W. J. 2003. Biology and conservation of sea turtles in Baja California, Mexico. PhD dissertation. University of Arizona, Tucson, USA. 474 p.

Peig, J. and A. J. Green. 2010. The paradigm of body condition: a critical reappraisal of current methods based on mass and length. Functional Ecology 24:1323-1332.

Pereira, S., E. H. S. M. Lima, L. Ernesto, H. Mathews and A. Ventura. 2006. Epibionts associated with Chelonia mydas from northern Brazil. Marine Turtle Newsletter 111:17-18.

Pfaller, J. B., K. A. Bjorndal, K. J. Reich, M. G. Frick and K. L. Williams. 2006. Distribution patterns of epibionts on the carapace of loggerhead turtles, Caretta caretta. Journal of the Marine Biological Association of the United Kingdom Biodiversity Records [internet] 5381:1-4; http://www.mba. ac.uk/jmba/jmba2biodiversityrecords..php; last access: 24.VII.2011.

Pfaller, J. B., M. G. Frick, K. J. Reich, K. L. Williams and K. A. Bjorndal. 2008. Carapace epibionts of loggerhead turtles (Caretta caretta) nesting at commercial National Seashore, Florida. Journal of Natural History 42:1095-1102.
Pritchard, P. C. H. 1999. Status of the black turtle. Conservation Biology 13:1000-1003.

Pritchard, P. C. H. and J. A. Mortimer. 1999. Taxonomy, external morphology, and species identification. Marine Turtle Specialist Group Publication 4:21-38.

R Development Core Team. 2008. R: A language and environment for statistical computing. $\mathrm{R}$ Foundation for Statistical Computing, Vienna, Austria. ISBN 3-900051-07-0, http:// www.R-project.org; last access: 24.VII.2011.

Rawson, P. D., R. Macnamee, M. G. Frick and K. L. Williams. 2003. Phylogeography of the coromulid barnacle, Chelonibia testudinaria, from loggerhead sea turtles, Caretta caretta. Molecular Ecology 12:2697-2706.

Reich, K. J., K. A. Bjorndal and A. B. Bolten. 2007. The 'lost years' of green turtles: using stable isotopes to study cryptic life stages. Biology Letters 3:712-714.

Schärer, M. T. 2001. A survey of the epibiota of hawksbill sea turtles (Eretmochelys imbricata) of Mona Island, Puerto Rico. Master's Thesis University of Puerto Rico. 82 p.

Seveneter, J. 1996. Aggregation and coexistence. I. Theory and analysis. Journal of Animal Ecology 65:297-307.

Stamper, M. A., G. Harms, S. D. Epperly, J. Brawn-McNeill, L. Avens and M. K. Stoskopf. 2005. Relationship between barnacle apibiotic loads and hematologic parameters in loggerhead sea turtles (Caretta caretta), a comparison between migratory and residential animals in Pamlico Sound, North Carolina. Journal of Zoo and Wildlife Medicine 36:635-641.

Withers, T. H. 1953.Catalogue of fossil Cirripedia in the department of geology. London: British Museum of Natural History.

Zardus, J. D. and M. G. Hadfield. 2004. Larval development and complemental males in Chelonibia testudinaria, a barnacle commensal with sea turtles. Journal of Crustacean Biology 24:409-421. 